\title{
CONSIDERATIONS REGARDING THE EVOLUTION OF ROLLER SPEED SKATING IN ROMANIA
}

\author{
Vaida Marius \\ Petroleum - Gas University of Ploiești
}

\begin{abstract}
The fact that in Romania, in the last years, this sport has experienced some regression in terms of number of practitioners is trying to establish whether this affects the achieved results, as the vast majority of the clubs that have speed skating sections still work. Sport selection is of particular importance in achieving the best sports performance, which should be carried out on a continuous basis.

This study aims to highlight the evolution of speed skating in our country between 2014-2019, for the senior category, at the national roller speed skating Championship. The events that were targeted in this study are 500m, $1000 \mathrm{~m}, 1500 \mathrm{~m}$ and $3000 \mathrm{~m}$ seniors (boys and girls) competitions. The first 3 (or 2, depending on the situation) results per year investigated were collected. The research methods used are: Bibliographic method, data collection and graphical method.

From the data shown above it can be noted that, with the exception of the years 2015/2016 (when poor results are most frequently shown) and in two cases during2018, the achieved results were improved in both girls and boys, in some cases the achieved progress being significant.

Although speed skating in Romania is not a sport as publicized as other sports branches, the results are on an ascending line, in the process of improving, which shows that trainers in our country have a level of knowledge comparable to other countries with tradition in the world, increasing funding and attracting sponsorship is one of the factors that can accelerate the advancement of athletes by increasing cantonal numbers, using state-of-the-art equipment, using effort supporters according to their preparation time and age, etc.
\end{abstract}

Keywords: speed skatingevolution, roller

\section{Introduction}

The fact that in Romania, in the last years, this sport has experienced some regression in terms of number of practitioners is trying to establish whether this affects the achieved results, as the vast majority of the clubs that have speed skating sections still work.

Richard J. Fisher and Jan Borms (1994, pp.27) pointed out that "although there is a large amount of information on the psychological and social profile of elite performance, the current knowledge pool does not allow the selection of talented sportsmen to be made solely on the basis of these data". 
Madella A. (2000, pp. 75) considers the problem of tracing children with a tendency to certain sports, to be at the center of discussions held by researchers, coaches and federations, international bodies, etc. The same author, Madella A. (2000, pp. 75), argues that the factors most used for the search and provision of talent are: "anthropometric and morphological criteria, conditional capacities, coordination capacities, psychological variables, functional parameters, environmental conditions, tolerance of specific loads and stress".

Psychological factors also play a very important role in achieving world-class sporting performances, the assessment of psychological attributes cannot be done without specialist guidance, because here, as in other areas, certain codes, ethical and procedural, must be respected. Richard J. Fisher and Jan Borgs (1994, pp. 31) considers that once the basic requirements are met, it should be possible to introduce more specialized screening methods, thus constituting more sophisticated profiles of young people involved in this complex process. Sports professionals consider sportspeople as "complex psychological bodies".

Until the results are achieved, speed skating operators must pass several stages, with precise objectives, means and criteria for action which differ from one stage to the next. C.N.E.F.S. (1987, pp. 14-15) classifies the steps above into four stages and shall be carried out according to the specialist federation as follows:

\section{"Stage I}

Objective: Screening and initiation (minimum duration one year).

- $\quad$ sports training groups in schools (5 hours a week);

- $\quad$ sports associations in schools (6 hours a week);

- local level sections for screening and initiation tasks;

- learning centers for sport branches

Means and criteria for acting:

- the system of assessing the overall physical training of pupils and tracing talent for performance sport;

- training programs for these forms;

- local competition system, at school level.

\section{Stage II}

Objective: Admission in organized forms of training, sport training.

- beginner groups for sports unit departments,

- advanced groups for sports units.

Means and criteria for action:

- evidence and rules for selection - general and specific to each sport branch; 
- branch-based training programs;

- local and county competitive system.

\section{Stage III}

Objective: Promoting and sport training

- the performance groups of the sports unit departments;

- county training centers for the juniors;

- national olympic junior training centers;

- national junior and youth lots;

- exceptions, in national lots of seniors.

Means and criteria for action:

- probes and rules specific to the level for selection;

- branch-based training programs;

- republican competitive system;

- official international competitive system.

\section{Stage IV}

Objective: Promoting and sport training

- high-performance groups of the olympic and international-level sections;

- olympic and national lots of seniors.

Means and criteria for acting:

- probeses and rules specific to the level for selection;

- training programs by each branch of sport;

- republican competitive system;

- official international competitive system."

\section{Material and methods}

This study aims to highlight the evolution of speed skating in our country between 2014-2019, in the senior category, at the national roller speed skating Championship. The events that were targeted in this study are 500m, 1000m, 1500m and 3000m seniors (boys and girls) competitions. The first 3 (or 2, depending on the case) results per year investigated were collected. The research methods used are: Bibliographic method, data collection and graphical method.

\section{Results}

The results are presented in the 4 tables and 9 graphs shown below. 
Table 1.Men $500 \mathrm{~m}$ and $1000 \mathrm{~m}$ results

\begin{tabular}{|c|c|c|c|c|c|c|}
\hline & \multicolumn{6}{|c|}{ SENIORS } \\
\hline & \multicolumn{2}{|c|}{$500 \mathrm{~m}$} & & \multicolumn{3}{c|}{$1000 \mathrm{~m}$} \\
& 1 st place & 2nd place & 3rd place & 1 st place & 2nd place & 3rd place \\
\hline 2014 & 0.44 .82 & 0.46 .32 & 0.45 .30 & 1.31 .57 & 1.32 .75 & 1.33 .12 \\
\hline 2015 & 0.45 .17 & 0.46 .64 & 0.49 .10 & 1.33 .70 & 1.37 .89 & 1.40 .36 \\
\hline 2016 & 0.44 .60 & 0.46 .13 & - & 1.33 .13 & 1.35 .26 & - \\
\hline 2017 & 0.43 .24 & 0.44 .52 & 0.44 .52 & 1.28 .64 & 1.29 .43 & 1.31 .22 \\
\hline 2018 & 0.43 .30 & 0.43 .52 & 0.43 .54 & 1.28 .65 & 1.30 .31 & 1.30 .79 \\
\hline 2019 & 0.42 .11 & 0.46 .55 & - & 1.26 .83 & 1.43 .37 & - \\
\hline
\end{tabular}

Table 2.Men $1500 \mathrm{~m}$ and $3000 \mathrm{~m}$ results

\begin{tabular}{|c|c|c|c|c|c|c|}
\hline & \multicolumn{6}{|c|}{ SENIORS } \\
\hline & \multicolumn{3}{|c|}{$1500 \mathrm{~m}$} & \multicolumn{3}{c|}{$3000 \mathrm{~m}$} \\
\hline & 1 st place & 2nd place & 3rd place & 1st place & 2nd place & 3rd place \\
\hline 2014 & 2.21 .27 & 2.22 .30 & 2.28 .34 & - & - & - \\
\hline 2015 & 2.23 .32 & 2.31 .92 & 2.33 .67 & 5.15 .02 & 5.30 .23 & 5.39 .02 \\
\hline 2016 & 2.25 .80 & 2.35 .23 & - & 5.20 .50 & 5.55 .54 & - \\
\hline 2017 & 2.20 .54 & 2.22 .60 & 2.25 .53 & 5.01 .74 & 5.14 .24 & 5.27 .37 \\
\hline 2018 & 2.17 .41 & 2.23 .70 & 2.24 .16 & 4.54 .45 & 5.09 .27 & 5.13 .29 \\
\hline 2019 & 2.13 .65 & 2.49 .15 & - & 4.53 .29 & 6.04 .29 & - \\
\hline
\end{tabular}

Table 3.Ladies 500m and $1000 \mathrm{~m}$ results

\begin{tabular}{|c|c|c|c|c|c|c|}
\hline & \multicolumn{5}{|c|}{ SENIORS } \\
\hline & \multicolumn{2}{|c|}{$500 \mathrm{~m}$} & \multicolumn{3}{c|}{$1000 \mathrm{~m}$} \\
\hline & 1st place & 2nd place & 3rd place & 1st place & 2nd place & 3rd place \\
\hline 2014 & 0.50 .10 & 0.62 .32 & - & 1.39 .64 & 2.11 .58 & - \\
\hline 2015 & 0.49 .13 & 0.50 .36 & 0.54 .02 & 1.40 .80 & 1.41 .76 & 1.51 .89 \\
\hline 2016 & 0.48 .92 & 0.49 .67 & 0.50 .11 & 1.38 .86 & 1.40 .82 & 1.40 .90 \\
\hline 2017 & 0.46 .51 & 0.47 .46 & 0.49 .83 & 1.34 .17 & 1.35 .46 & 1.41 .13 \\
\hline 2018 & 0.44 .61 & 0.46 .51 & 0.47 .45 & 1.29 .68 & 1.32 .60 & 1.35 .40 \\
\hline 2019 & 0.44 .40 & 0.44 .75 & 0.45 .19 & 1.29 .57 & 1.29 .72 & 1.32 .57 \\
\hline
\end{tabular}

Table 4.Ladies $1500 \mathrm{~m}$ and $3000 \mathrm{~m}$ results

\begin{tabular}{|c|c|c|c|c|c|c|}
\hline & \multicolumn{6}{|c|}{ SENIORS } \\
\hline & \multicolumn{3}{|c|}{$1500 \mathrm{~m}$} & \multicolumn{3}{c|}{$3000 \mathrm{~m}$} \\
\hline & 1 st place & 2nd place & 3rd place & 1st place & 2nd place & 3rd place \\
\hline 2014 & 2.33 .70 & 3.28 .29 & - & 8.24 .24 & 10.29 .76 & - \\
\hline 2015 & 2.33 .48 & 2.35 .23 & 2.55 .89 & 5.23 .31 & 5.33 .26 & 6.12 .70 \\
\hline 2016 & 2.33 .64 & 2.36 .95 & 2.38 .60 & 5.23 .64 & 5.33 .00 & 5.34 .67 \\
\hline 2017 & 2.26 .21 & 2.26 .91 & 2.34 .48 & 5.07 .60 & 5.11 .47 & 5.28 .58 \\
\hline 2018 & 2.20 .45 & 2.21 .56 & 2.27 .73 & 5.07 .54 & 5.11 .23 & 5.11 .27 \\
\hline 2019 & 2.18 .15 & 2.21 .12 & 2.21 .36 & 5.02 .38 & 5.04 .49 & 5.17 .92 \\
\hline
\end{tabular}




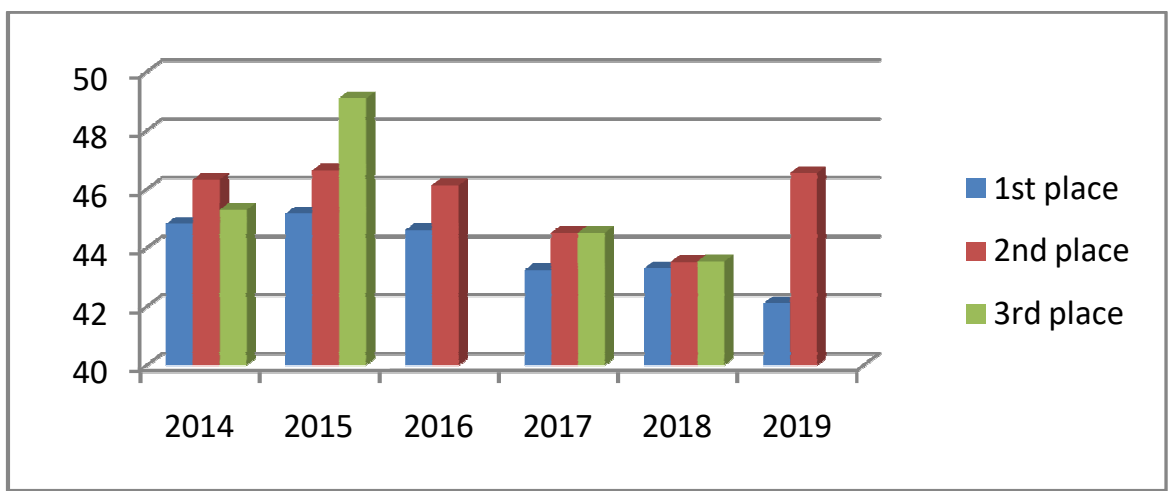

Figure 1. The performance for the $500 \mathrm{~m}$ Men

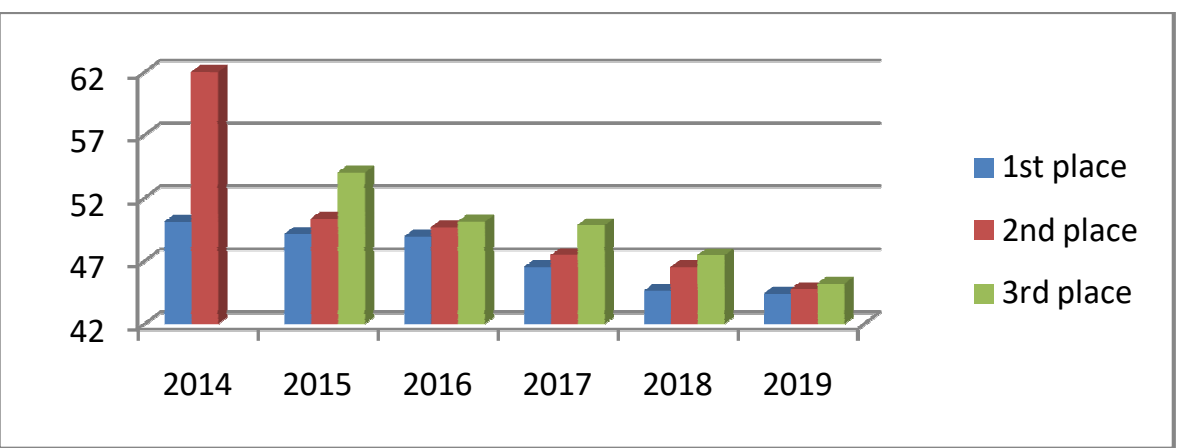

Figure 2. The performance for the $500 \mathrm{~m}$ Ladies

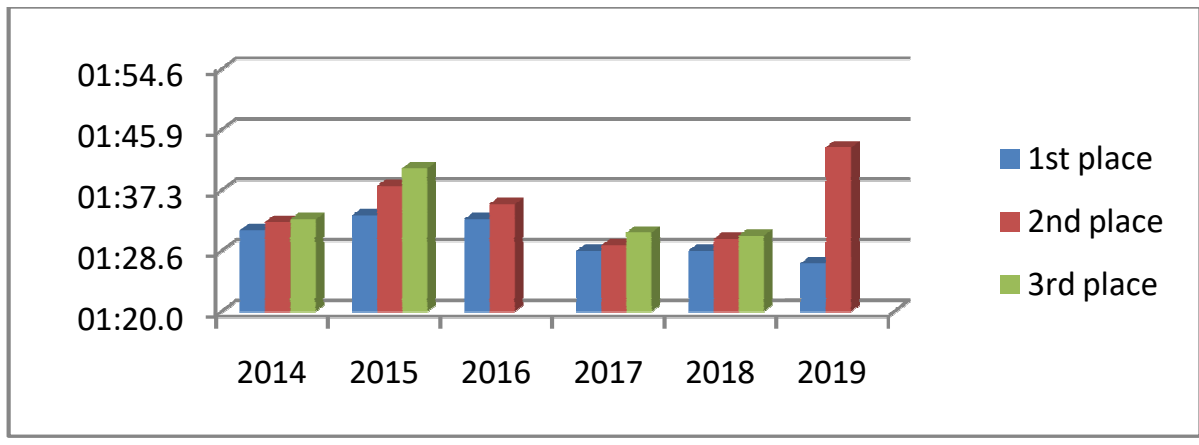

Figure 3.The performance for the $1000 \mathrm{~m}$ Men

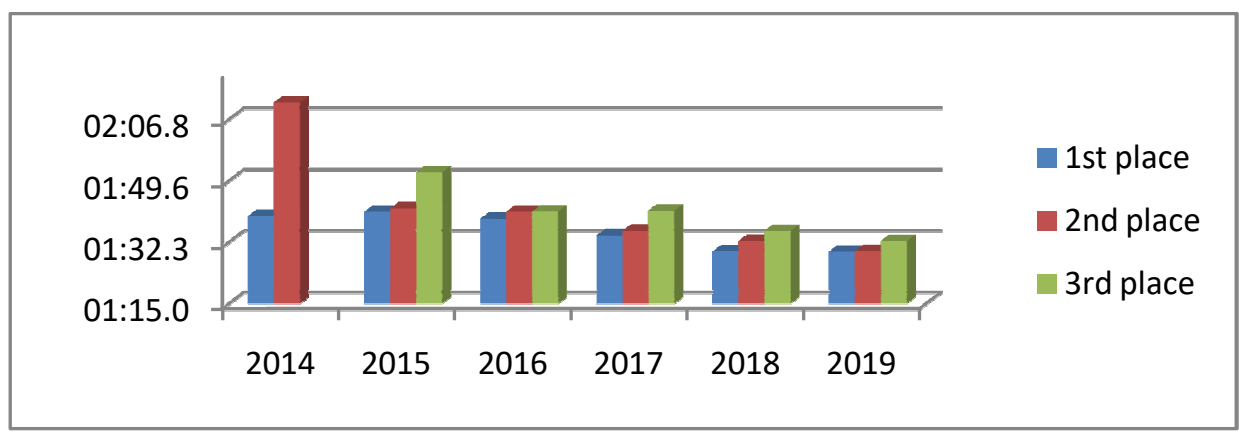

Figure 4.The performance for the $1000 \mathrm{~m}$ Ladies 


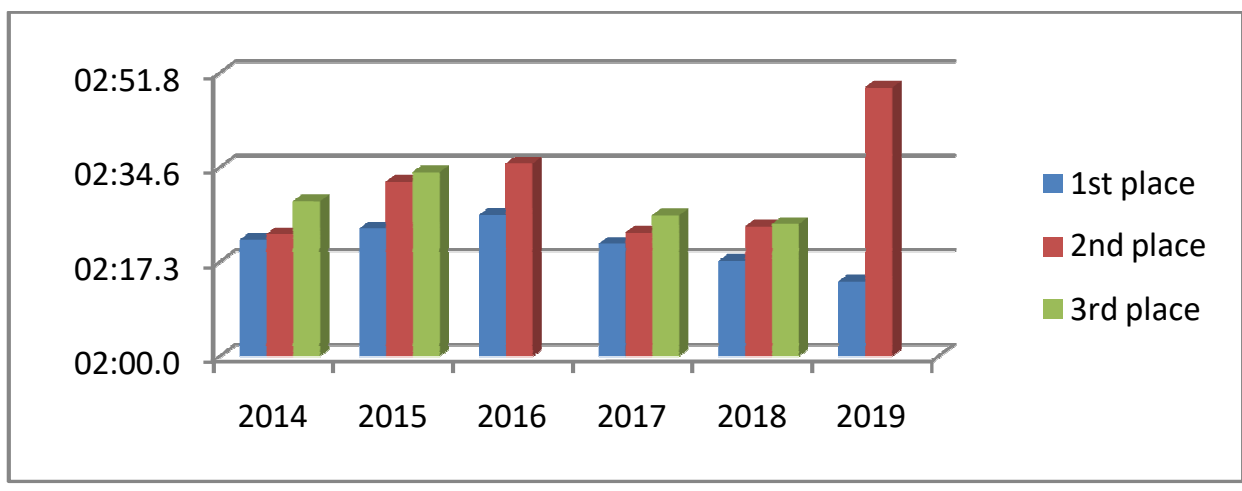

Figure 5.The performance for the $1500 \mathrm{~m}$ Men

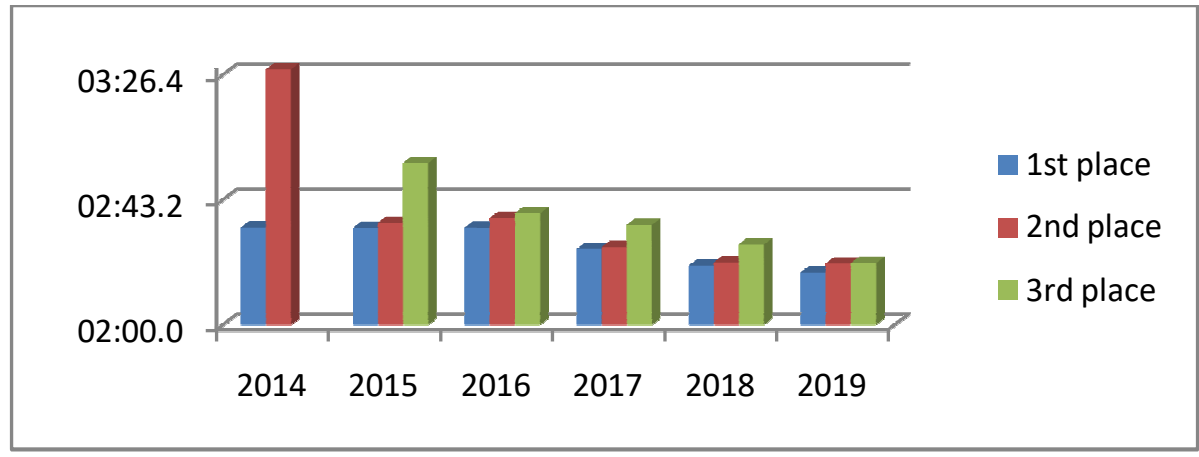

Figure 6.The performance for the $1500 \mathrm{~m}$ Ladies

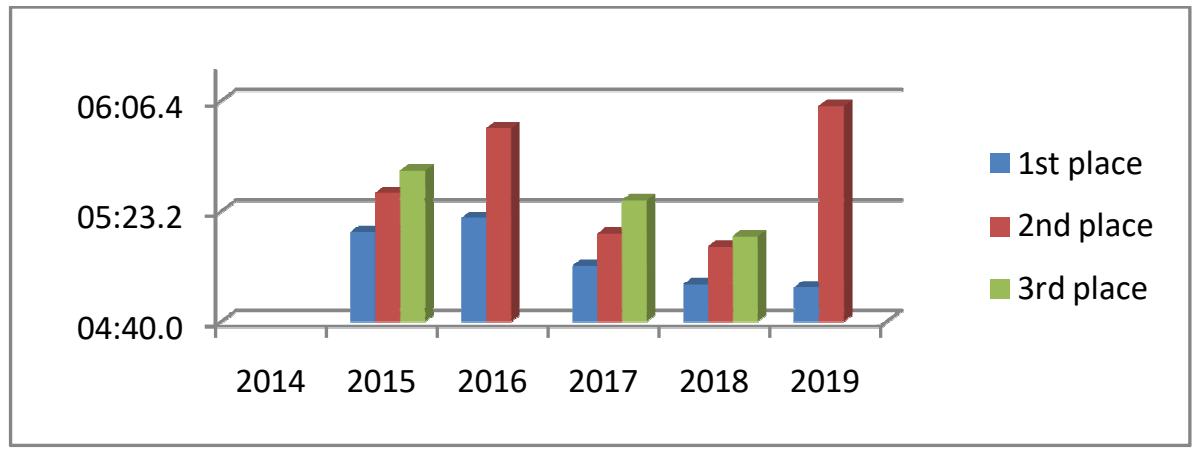

Figure 7.The performance for the $3000 \mathrm{~m}$ Men

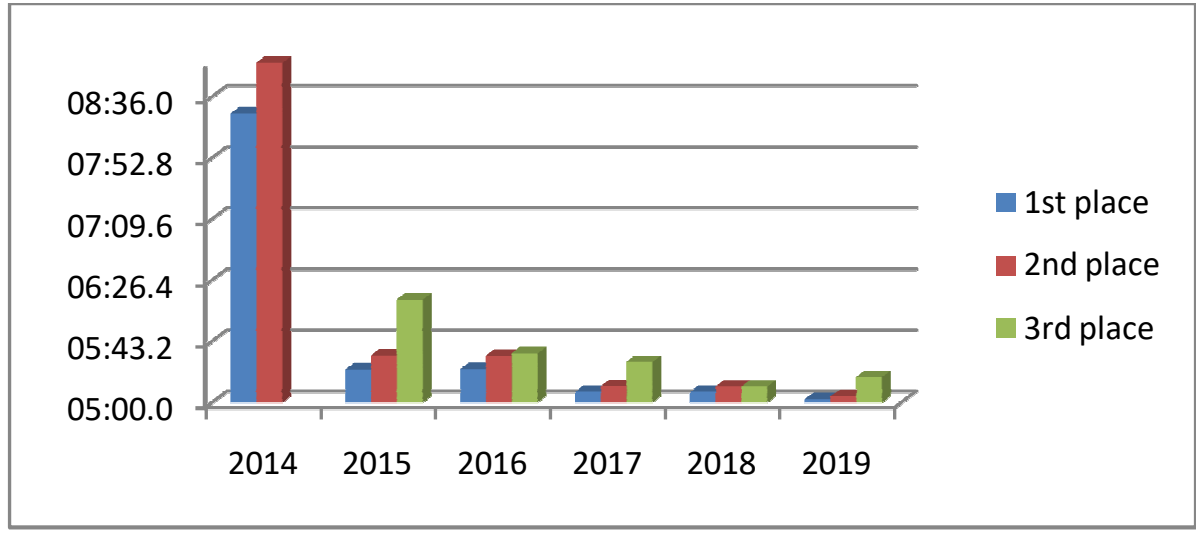

Figure 8.The performance for the $3000 \mathrm{~m}$ Ladies 


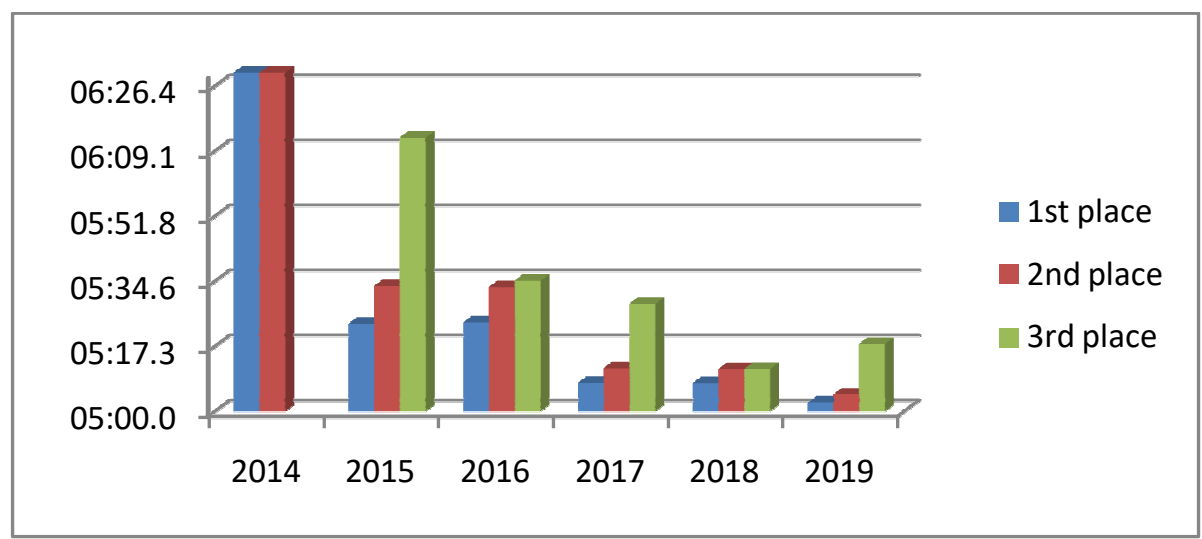

Figure 9.The performance for the $3000 \mathrm{~m}$ Ladies

\section{Discussions}

As shown above, a constant development can be observed in the $500 \mathrm{~m}$ girl test competition in the 6 years studied, starting from 50,10 sec in 2014 and reaching 44,40 sec in 2019. The boys' competition, with the exception of 2015 and 2018, shows progress, starting from 44,82 sec in 2014 and reaching 42,11 sec in 2019.

The $1000 \mathrm{~m}$ competition shows a lower result in girls in 2015 , and for the rest of all the years studied, an improvement in the results is observed, starting from 1:39.64 min in 2014 and reaching 1:29.57 $\min$ in 2019, with considerable improvement in results. In the same competition, in boys, the improvement of the six years is lower compared to girls, except for 2015 and 2018 where the results were worse than the previous year, progress is noted, the results being 1:31,57 $\mathrm{min}$ in 2014 and 1:26,83 $\mathrm{min}$ in 2019.

The $1500 \mathrm{~m}$ competition is characterized by a considerable development of results of the six years, with the exception of 2016, as the results have been improved from 2:33,70 min in 2014 to $2: 18,15 \mathrm{~min}$ in 2019 . The $1500 \mathrm{~m}$ boys' competition is characterized by weaker results in the years 2015 and 2016, followed by a steady improvement in results until 2019. In 2014 the best result was 2:21,27 min compared to 2019 where the result of 2:13,65 min stands out.

The longest distance evaluated is the $3000 \mathrm{~m}$ run, where 2014 results are low for the girls (8:24,24 $\mathrm{min}$ ) compared to 2019 where the best result was 5:02,38 min. Excepting 2016 (which' results are close to 2015), for all the years studied, values have improved. In the $3000 \mathrm{~m}$ boys' competition, the study has been carried out since 2015 because in 2014 there is no data, with the evolution of the best result being constant, except for 2016 where the results are poor. In 2015 the best result was $5: 15,02$ min compared to 2019 when the result was 4:53,29 min. 


\section{Conclusions}

From the data shown above, it can be noted that, with the exception of the years 2015/2016 (when poor results are most frequently shown) and in two cases during 2018, the achieved results have been improved in both girls and boys, in some cases the progress achieved being significant.

Although speed skating in Romania is not a sport as publicized as other sport branches, the results are on an ascending line, in the process of improving them, which shows that trainers in our country have a level of knowledge comparable to other countries with tradition in the world, increasing funding and attracting sponsorship is one of the factors that can accelerate the advancement of athletes by increasing cantonal numbers, using state-of-the-art equipment, using effort supporters according to their preparation time and age, etc.

The human resource in Romania is of quality, the athletes in our country achieve good results compared to other countries where this sport is considered national sport and which have much higher funds but also state-of-the-art equipment. I make a parallel to the speed skating on ice, where athletes from our country benefit from specific track training clubs of $400 \mathrm{~m}$ on average maximum one month per year, compared to countries where training is carried out for 11 months.

Another incentive for children would be to increase the prizes for results achieved at national level and not only at world level, which would even encourage the broadening of the selection base by registering as many children as possible in speed skating clubs as a performance section.

\section{References}

1. C.N.E.F.S. (1987), Criterii, probe şi norme pentru selecţia în patinaj, uz intern, București.

2. Fisher B.J., Borms J. (1994) - În căutarea excelenţei sportive, S.C.J. 1(98) Bucureşti.

3. Madella A. (2000) Talentul Sportiv - C.C.P.S., S.C.J. Nr. 120-121 Bucureşti.

4. Patinaj (1991), FederaţiaRomână de Patinaj, U.I.P. Nr. 29, Bucureşti.

5. http://www.frponline.ro/arhiva.html

6. https://www.isu.org/ 